\title{
Design of a Novel Photocatalytic Gypsum Plaster: with the Indoor Air Purification Property
}

\author{
Q.L. $\mathrm{Yu}^{1, \mathrm{a}}$ and H.J.H. Brouwers ${ }^{1, b}$ \\ ${ }^{1}$ Department of the Built Environment, Eindhoven University of Technology, P. O. Box 513, 5600 MB \\ Eindhoven, the Netherlands \\ aq.yu@bwk.tue.nl, bjos.brouwers@tue.nl
}

Keywords: gypsum plaster; heterogeneous photocatalytic oxidation, indoor air quality improvement.

\begin{abstract}
This article addresses the design of a new photocatalytically active gypsum plaster. A hemihydrate in beta type is used as binder to design this material and a carbon modified $\mathrm{TiO}_{2}$ that can be activated by visible light is used as photocatalyst. An own developed test setup to assess the indoor air purification capacity of the developed material is presented. The new product possesses the indoor air pollutants removal capacity. The air pollutants removal ability is related with not only the dosage of the applied photocatalyst but also strongly with the physical property of the resulting matrix such as the porosity.
\end{abstract}

\section{Introduction}

Indoor air quality (IAQ) has received great attention because of the very important role it plays on human comfort and health. The US Environmental Protection Agency pointed out that indoor air pollution poses a greater risk than outdoor air pollution because people spend $80-90 \%$ of their time indoors. In fact, indoor air pollution was listed in 2009 as one of the major causes for cancer [1]. So, it is of vital importance to remove the indoor air pollutants to improve the IAQ. Traditional air purifying methods such as controlling pollutant sources, increasing air exchange and using air purifiers have certain disadvantages. Source control is difficult to achieve in many places. Increasing the air exchange may even transport more pollutants from the outdoor environment. Common air purifiers often use sorption materials to adsorb gases or odors which only transfer the contaminants to another phase rather than eliminating them and additional disposal or handling steps are subsequently required.

The present study addresses the development of a novel gypusm plaster plaster applying the heterogeneous photocatalytic oxidation (PCO) technology. PCO is a process involving a nano-solid semiconductor catalyst, e.g. titanium dioxide $\left(\mathrm{TiO}_{2}\right)$, which can be activated by ultraviolet light $[2,3]$. PCO has been investigated as an effective method for water or air purification due to: (1) the PCO only needs solar light irradiation with suitable wavelength and can be spontaneously triggered when the photocatalyst is under irradiation, (2) the widely used photocatalyst $\mathrm{TiO}_{2}$ is inexpensive, chemically stable and has high efficiency, (3) it can degrade most of the indoor air pollutants, (4) no other additives are required. However, pure $\mathrm{TiO}_{2}$ can only be activated by UV radiation, which only amounts to $0.001-0.05 \mathrm{~W} / \mathrm{m}^{2}$ under indoor conditions. Therefore, here a modified $\mathrm{TiO}_{2}$ is applied, which can be activitaed by visible light due to the extended absorption ability of the catalyst to visible light spectrum. Gypsum plaster is widely used as indoor funishing material, in the present study it is used as substrate for the application of the photocatalyst. An accelerator is used to adjust the setting of the designed material.

\section{Experimental}

Calcium sulphate systems are characterized by three solid phases, depending on the stoichiometric amount of the crystallized water: calcium sulphate dihydrate (also called gypsum, $\mathrm{CaSO}_{4} \cdot 2 \mathrm{H}_{2} \mathrm{O}$ ), calcium sulphate hemihydrate $\left(\mathrm{CaSO}_{4} \cdot 0.5 \mathrm{H}_{2} \mathrm{O}\right.$, including the $\alpha$ - and $\beta$-types $)$ and calcium sulphate 
anhydrite $\left(\mathrm{CaSO}_{4}\right)$ [4]. Gypsum plaster (calcium sulphate hemihydrate in $\beta$-type) was already used in Egyptian pyramids at least 4000 years ago [5], and is still extensively applied in buildings along with other cementitious materials such as cement and lime. In the present study, a commercially available photocatalyst, a carbon doped $\mathrm{TiO}_{2}$ kindly provided by Kronos International (Germany), is chosen to be used here. The basic properties of the used photocatalyst is listed in Table 1.

Table 1: The basic properties of the used photocatalyst.

\begin{tabular}{cc}
\hline Parameter & Photocatalyst \\
\hline $\mathrm{TiO}_{2}$ content (ISO 591) & $>87.5 \%$ \\
Crystal modification & anatase \\
Density (ISO 787, Part 10) & $3.9 \mathrm{~g} / \mathrm{cm}^{3}$ \\
Crystallite size & approx. $15 \mathrm{~nm}$ \\
Specific surface area (BET) & $>225 \mathrm{~m}^{2} / \mathrm{g}$ \\
Bulk density & $350 \mathrm{~g} / 1$ \\
Max. processing temperature & $150{ }^{\circ} \mathrm{C}$ \\
Application pH-range & $4-9$
\end{tabular}

Five mixes are designed here and are listed in Table 2. A detailed mixing procedure as well as curing method can be found in [6].

Table 2: Mix design of the PCO gypsum plaster.

\begin{tabular}{ccccc}
\hline Materials & $\begin{array}{c}\beta \text {-hemihydrate } \\
(\mathrm{g})\end{array}$ & $\begin{array}{c}\text { Photocatalyst } \\
(\mathrm{g})\end{array}$ & $\begin{array}{c}\text { Water } \\
(\mathrm{g})\end{array}$ & $\begin{array}{c}\text { Accelerator } \\
(\mathrm{g})\end{array}$ \\
\hline Mix 1 & 255.9 & 7.68 & 166.3 & 0 \\
Mix 2 & 255.9 & 12.8 & 166.3 & 0 \\
Mix 3 & 224.1 & 6.73 & 190.4 & 1.68 \\
Mix 4 & 224.1 & 11.21 & 190.4 & 1.68 \\
Ref & 255.9 & 0.0 & 166.3 & 0 \\
\hline
\end{tabular}

$\mathrm{NO}$ are generated from the reaction of nitrogen and oxygen gases in the air during combustion, especially at high temperatures. The two major emission sources are transportation vehicles and stationary combustion sources such as electric utilities and industrial boilers, as well as indoor sources such as cooking, heating and smoking. NO is a typical inorganic pollutants available indoors. Therefore, here NO is chosen as the target pollutant to assess the PCO performance. The ISO standard 22197-1: 2007 is used as a reference to perform the PCO experiments.

An own developed test setup following ISO standard 22191-1:2007 as a reference is used here to carry out the PCO experiments, as shown in Figure 1. The reactor, made from non-adsorbing plastic materials with a size of $100 \times 200 \mathrm{~mm}^{2}(\mathrm{~W} \times \mathrm{L})$, allows a flat sample to be embedded. After placing the test sample inside, the top of the reactor is tightly covered with a plate made from borosilicate glass allowing UV and/or visible light to pass through with almost no resistance. A more detailed description is presented in Hüsken et al. [7] and Yu and Brouwers [8]. The reactor's height, which is the distance between the paralleled surface of the test sample and the covering glass plate, can be adjusted by screws in the bottom of the reactor. The target pollutant gas can only pass through the reactor along the longitudinal direction by means of appropriate sealing. 
Visible light is used in the experiment. The applied light source consists of three cool day light lamps of $25 \mathrm{~W}$ each (Philips, the Netherlands), emitting a visible radiation in the range of 400-700 $\mathrm{nm}$. The irradiance can be adjusted by a light intensity controller. The light intensity is measured with a VIS-BG radiometer (Dr. Gröbel UV-Elektronik GmbH, Germany). The VIS-BG radiometer measures a wavelength range of 400-600 $\mathrm{nm}$ with the maximum relative sensitivity at about $460 \mathrm{~nm}$. The reason that the VIS-BG radiometer with this range is chosen lies in the characteristics of the photocatalyst used in the experiment. The used carbon-doped $\mathrm{TiO}_{2}$ can be activated until the bluish green light region which is the same as the measurement range that the radiometer has. The VIS-BG has a measuring range of $2000 \mathrm{~W} / \mathrm{m}^{2}$ with the resolution of $0.1 \mathrm{~W} / \mathrm{m}^{2}$.

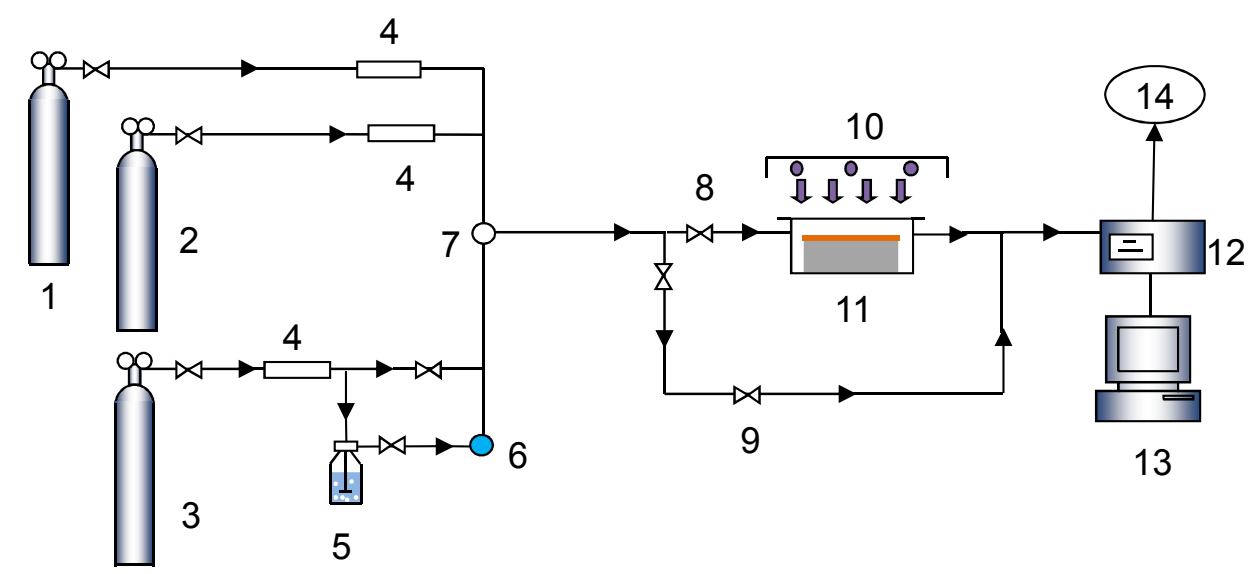

Figure 1: Schematic diagram of photocatalytic degradation set-up. 1. NO gas supply. 2. $\mathrm{NO}_{2}$ gas supply. 3. Synthetic air supply. 4. Mass controller meter. 5. Humidifier. 6. Humidity controller. 7. Temperature and relative humidity sensor. 8. Valve. 9. Valve. 10. Light source. 11. Reactor. $12 . \mathrm{NO}_{\mathrm{x}}$ analyzer. 13. Computer. 14 Vent.

NO is used as target pollutant. The used gas consists of $50 \mathrm{ppm}$ NO stabilized in nitrogen $\left(\mathrm{N}_{2}\right)$. Because the final target NO concentration ranges in the order of ppb with the maximum concentration of $1.0 \mathrm{ppm}$, a transport fluid synthetic air which is composed of $20.5 \mathrm{vol} \%$ of oxygen $\left(\mathrm{O}_{2}\right)$ and 79.5 vol.\% of $\mathrm{N}_{2}$ is employed, which is humidified by flowing through a demineralized water filled bottle. The target concentration of NO is adjusted by the the mass controller meters. Pollutant (NO) and intermediate product $\left(\mathrm{NO}_{2}\right)$ are analyzed using a chemiluminescent $\mathrm{NO}_{\mathrm{x}}$ analyzer (HORIBA 370, Japan). The analyzer, with a detection limit of $0.5 \mathrm{ppbv}$, measures the concentration in steps of 5 seconds. During the measurement, the analyzer constantly samples gas with a rate of $0.8 \mathrm{~L} / \mathrm{min}$.

A standard experimental condition is set in the present study as follows. An initial NO concentration is chosen as $500 \mathrm{ppb}$ and the volumetric flow rate of $3.0 \mathrm{~L} / \mathrm{min}$; the visible light intensity is $10.0 \mathrm{~W} / \mathrm{m}^{2}$ and the relative humidity of $50 \%$. The experiments are carried out at room temperature.

\section{Results analysis}

The photocatalytic oxidation reaction takes place immediately when the sample is exposed to the visible light. After reaching the maximum degradation rate, the process will slightly slow down and reach a stable conversion condition finally. Figure 2 shows a typical concentration change of $\mathrm{NO}_{\mathrm{x}}$ during the photocatalytic oxidation reaction. 


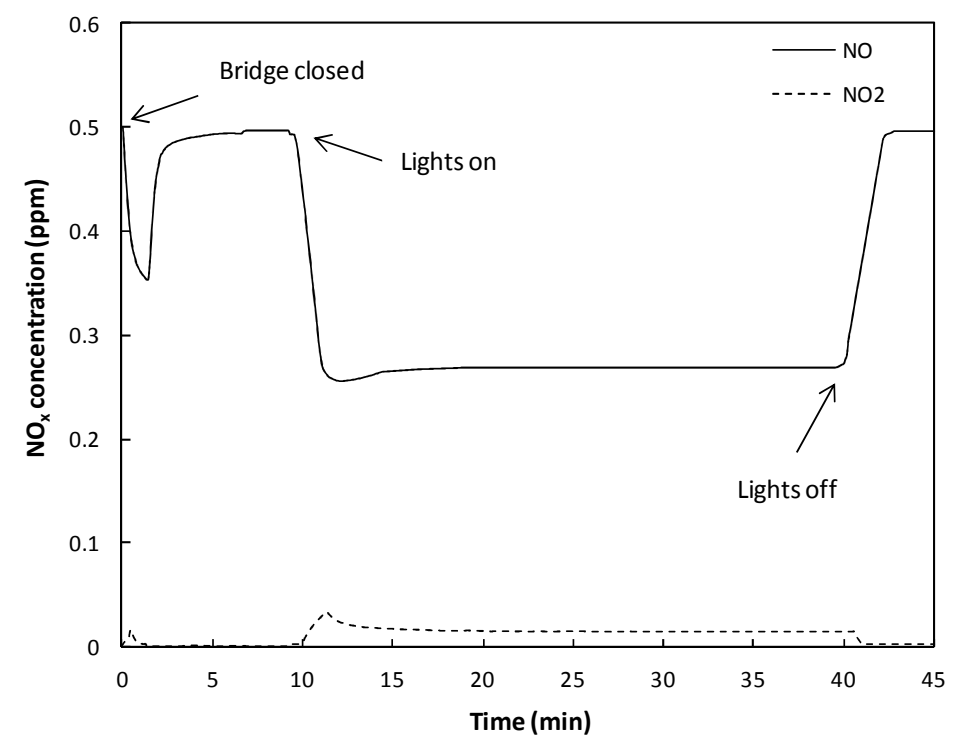

Figure 2: Schematic diagram of the NO concentration change during a measurement.

The photocatalytic oxidation efficiency of NO is calculated from:

$$
N O_{c o n}(\%)=\frac{C_{N O, \text { in }}-C_{N O, \text { out }}}{C_{N O, \text { in }}} \times 100 \%
$$

where $C_{N O \text {,out }}$ is defined as the average $\mathrm{NO}$ concentration during the last 5 minutes of the measurement (ppb).

However, not all the produced $\mathrm{NO}_{2}$ can be oxidized to $\mathrm{HNO}_{3}$ because a small part of it is released into the air due to desorption. So even when NO is used as single pollutant, the pollutants at the exit are composed of undegraded $\mathrm{NO}$ and the formed intermediate $\mathrm{NO}_{2}$. Therefore, the $\mathrm{NO}_{\mathrm{x}}$ conversion is used to study the influence of the experimental conditions since $\mathrm{NO}_{2}$ is an undesired intermediate pollutant. The $\mathrm{NO}_{\mathrm{x}}$ conversion is calculated from:

$$
N O_{x, \text { con }}(\%)=\frac{C_{N O_{x}, \text { in }}-C_{N O_{x}, \text { out }}}{C_{N O_{x}, \text { in }}} \times 100 \%
$$

where $C_{N O_{x} \text {,out }}$ is defined as the average $\mathrm{NO}_{\mathrm{x}}$ concentration during the last 5 minutes of the measurement (ppb).

The results are listed in Table 3.

Table 3: PCO test results with the photocatalytic gypsum plaster.

\begin{tabular}{ccc}
\hline $\begin{array}{c}\text { Sample } \\
\text { No. }\end{array}$ & $\begin{array}{c}\mathrm{NO}_{\text {con }} \\
(\%)\end{array}$ & $\begin{array}{c}\mathrm{NO}_{\text {X,con }} \\
(\%)\end{array}$ \\
\hline Mix 1 & 15.0 & 8.9 \\
Mix 2 & 33.2 & 23.7 \\
Mix 3 & 22.0 & 14.9 \\
Mix 4 & 32.5 & 22.7 \\
Reference & 0.0 & 0.0
\end{tabular}


It can be clearly observed that the idea of dosing photocatalyst to degrade the indoor air pollutant is working. With a dosage of $\mathrm{TiO}_{2}$ of $3 \%$ by mass of the $\beta$-hemihydrate, samples of Mix 1 and Mix 3 already show considerable $\mathrm{NO}$ and $\mathrm{NO}_{\mathrm{x}}$ conversion rates. This indicates that the photocatalytic oxidation technique can be a promising technology for the indoor air quality improvement.

Table 4: Dosage of the used photocatalyst.

\begin{tabular}{cccc}
\hline Sample No. & $\mathrm{w}_{0} / \mathrm{h}_{0}$ & \multicolumn{2}{c}{$\begin{array}{c}\text { Photocatalyst } \\
\text { Dolumetric proportion } \\
(\%)\end{array}$} \\
\hline Mix 1 & 0.65 & 3.0 & 0.74 \\
Mix 2 & 0.65 & 5.0 & 1.23 \\
Mix 3 & 0.85 & 3.0 & 0.62 \\
Mix 4 & 0.85 & 5.0 & 1.03 \\
\hline
\end{tabular}

The photocatalytic oxidation reaction is a surface reaction, i.e. the reaction only occurs on the surface of the photocatalyst. Therefore, the PCO performance would increase if the dosage of the photocatalyst increases, which is confirmed by the present result (see results of Mix 1 and Mix 2, and Mix 3 and Mix 4, respectively in Table 2). However, this does not mean that the more photocatalyst is used, the higher PCO efficiency is resulted. The PCO is also related to many other factors such as the photocatalyst surface area, the porosity of the substrate, surface roughness of the substrate etc.

Table 4 shows the volumetric proportion (VP) of the used photocatalyst in the matrix of the produced PCO gypsum plaster. It can be seen that although the VP of Mix 3 is lower than that of Mix 1, the PCO efficiency of Mix 1 is higher. This probably can be explained by the larger porosity of the gypsum plaster produced from Mix 3 (a larger water/hemihydrate ratio), which contributes to a higher pollutant absorption which in turn leads to a higher degradation rate of $\mathrm{NO}_{\mathrm{x}}$.

\section{Summary}

This article addresses the development of a novel gypsum plaster with the indoor air quality improvement property. A $\beta$-hemihydrate is used as binder and one type of carbon doped $\mathrm{TiO}_{2}$ is used as the photocatalyst. The following conclusions are drawn:

(1) A new gypsum based product is presented. The experimental results indicate that the photocatalytic oxidation is an effective indoor air purification technology. All photocatalytic oxidation experiments are carried out at ambient conditions under visible light, which shows its convenience for the indoor air purification.

(2) Both the physical properties (e.g. the porosity) of the gypsum plaster and the dosage of the photocatalyst affect the NO degradation efficiency. Further investigation is still necessary, for instance to address the long term behavior of the developed material.

\section{Acknowledgements}

The authors wish to express their appreciations to Prof. H. Hummel and Mrs. K. Engelhardt from Knauf Gips KG (Germany) for gypsum related material supply and Dr. Ch. Hampel for Sika Technology AG (Switzerland) from the superplasticizer supply. They furthermore express their gratitude to the following sponsors: Bouwdienst Rijkswaterstaat, Graniet-Import Benelux, Kijlstra Betonmortel, Struyk Verwo, Attero, Enci, Provincie Overijssel, Rijkswaterstaat Directie Zeeland, A\&G Maasvlakte, BTE, Alvon Bouwsystemen, V.d. Bosch Beton, Selor, Twee "R" Recycling, GMB, Schenk Concrete Consultancy, Geochem Research, Icopal, BN International, APP All Remove, Consensor, Eltomation, Knauf Gips KG, Hess ACC Systems, Kronos International, and Joma International AS (chronological order of joining). 


\section{Corresponding Author}

Dr. Q.L. Yu did his PhD research under the supervision of Prof. Dr. Ir. H.J.H. Brouwers in the Department of the Built Environment at Eindhoven University of Technology (the Netherlands) and received his $\mathrm{PhD}$ degree in May 2012. Currently he is a Post-Doctoral researcher at the same group. His research focuses on the design and development of sustainable building materials with multidisciplinary approaches applying materials science, civil engineering science and environmental engineering science, and his contact information is: email: q.yu@bwk.tue.nl, telephone: +31 (0)402472371.

\section{References}

[1] World Health Organization (2009). Mortality and burden of disease attributable to selected major risk. Global Health Risks. ISBN 978-92-4-156387.

[2] A. Fujishima, and K. Honda, Electrochemical photolysis of water at a semiconductor electrode. Nature 238(5358) 1972 37-38.

[3] G. Hüsken, M. Hunger, and H.J.H. Brouwers, Experimental study of photocatalytic concrete products for air purification. Build. and Environ. 44(12) 2009 2463-2474.

[4] F. Wirsching, Calcium Sulfate. Wiley-VCH Verlag GmbH \& Co. KGaA, Weinheim, 2005.

[5] J.V. Ryan, Study of gypsum plasters exposed to fire. Journal of research of the national bureau of standards-C. Eigin. and Instru. 66C(4) 1962 373-387.

[6] Q.L. Yu, H.J.H. Brouwers, Microstructure and mechanical properties of $\beta$-hemihydrate produced gypsum:An insight from its hydration proces. Const. Build. Mater. 25 (2011) 3149-3157.

[7] G. Hüsken, M. Hunger, and H.J.H. Brouwers, Comparative study on cementitious products containing titanium dioxide as photo-catalyst. In Baglioni, P., Cassar, L. (eds.). Proceedings International RILEM Symposium on Photocatalysis, Environment and Construction Materials-TDP. RILEM Publications, Bagneux, France, 2007 147-154.

[8] Q.L., Yu, and H.J.H. Brouwers, Indoor air purification using heterogeneous photocatalytic oxidation. Part I: experimental study. Appl. Catal. B-Environ. 922009 454-461. 